\title{
HUBUNGAN ASPEK EKSISTENSIAL DENGAN DERAJAT DEPRESI PADA LANSIA DI BPSTW PROVINSI JAWA BARAT
}

\author{
Khrisna Wisnusakti ${ }^{1, *}$, Aat Sriati ${ }^{2}$ \\ ${ }^{1}$ Program Studi Prodi Ners, \\ Sekolah Tinggi Ilmu Kesehatan Jenderal Achmad Yani Cimahi, Indonesia \\ ${ }^{2}$ Fakultas Keperawatan, Universitas Padjadjaran, Bandung, Indonesia \\ *)E-mail: Khrisnaws@gmail.com
}

\begin{abstract}
ABSTRAK
Tujuan: Penelitian ini bertujuan mengetahui hubungan antara Aspek eksistensial dengan depresi pada lansia. Metode: Penelitian ini merupakan penelitian kuantitatif dengan menggunakan pendekatan korelasional dilakukan secara potong lintang. Populasi pada penelitian ini adalah lansia di Balai Perlindungan Sosial Tresna Werdha (BPTSW) Ciparay Teknik pengambilan sampel dengan total sampling. Jumlah sampel pada penelitian ini 129 responden. Kuesioner untuk mengukur aspek eksistensial menggunakan spiritual well being scale (SWBS), dan untuk mengukur depresi menggunakan Geriatric Depression Scale15 (GDS-15). Uji Korelasi menggunakan Uji Spearman. Hasil: dari 129 responden yang diteliti, tidak depresi $40,3 \%$, depresi ringan $42,6 \%$, depresi sedang $16,3 \%$, dan depresi berat $0,8 \%$. Sedangkan aspek eksistensial 59,7\% tinggi, 31,0\% sedang, dan 9,3\% rendah. Dari hasil uji korelasi terdapat hubungan yang signifikan antara aspek religius dengan derajat depresi pada lansia $(p<0,001)$ dengan korelasi sedang $(-0,533)$. Kesimpulan: semakin tinggi kesejahteraan spiritual lansia maka semakin rendah tingkat depresi lansia tersebut. Diharapkan pihak panti mampu mempertahankan dan lebih meningkatkan kegiatan keagamaan bagi para lansia untuk memenuhi kebutuhan spiritualnya. Lansia harus sering diberi bimbingan dan pengetahuan terutama dalam hal keagamaan. Sehingga lansia diharapkan mampu untuk mengatasi masalah yang dihadapi serta terhindar dari depresi.
\end{abstract}

Kata kunci: Eksistensial, depresi, lansia

\section{The Relationship Between Spiritual Welfare and Depression in Elderly Citizens in BPTSW East Java Province}

\section{ABSTRACT}

Objective: The research investigates the relationship between spiritual welfare and depression in elderly citizens. Methods: The study applied the quantitative method by focusing on correlational approaches applied in cross-sectional manner. A total of 129 respondents from the BPTSW Ciparay senior residents took part in this study with the total sampling process. Questionnaires to measure welfare levels using a spiritual well being scale (SWBS) and for measuring depression using Geriatric Depression Scale 15 (GDS-15). Data was analysed with Spearman correlation test. Results: Results showed that from 129 respondents 40,3\% respondents were not experiencing depression 42,6\% respondents were experiencing mild depression, 16,3\% respondents were experiencing medium depression, and 0,8\% respondent was with a heavy depression. Regarding their spiritual levels, 59,7\% respondents indicated that they were at high level, $31,0 \%$ respondents at medium level, and 9,3\% respondents at low level. The correlation test showed a relationship between the spiritual level and the level of depression in elderly residents $(p<0.001)$ with a moderate correlation $(-0.533)$. Conclusion: It can be concluded that the spiritual level reciprocates depression levels in elderly citizens. Thus, the results should be a consideration in increasing spiritual activities to fulfill their spiritual needs. So the elderly are expected to overcome the problems encountered and avoid depression.

Keywords: eksisitencia, depression, elderly residents 


\section{LATAR BELAKANG}

Pada usia lanjut akan terjadi berbagai kemunduran pada organ tubuh. Dengan terjadinya kemunduran organ dan perubahan psikis yang terjadi pada lansia, maka lansia rentan mengalami gangguan fisik dan gangguan mental (Chalise, 2014). Tidak semua lansia mengalami gangguan fisik dan mental (Ferszt, dkk, 2015).

Proses menua merupakan hal yang alami pada setiap manusia dan tidak dapat di hindari. Pada proses menua ini individu akan mengalami perubahan biologis, psikologis, sosial, dan spiritual (Montesó, dkk, 2011). Perubahan yang terjadi pada aspek biologis disebabkan oleh terjadinya penurunan anatomi dan fungsional organ. Perubahan morfologik degenaratif tersebut dialami pada sistem gastrointestinal, sistem kardiovaskuler, sistem respirasi, sistem pengaturan suhu tubuh, sistem genitauria, infeksi dan imunologi serta pada otot dan tulang (Boedhi-Darmojo \& Martono, 2009; Wahjudi, 2008; Stanley \& Beare, 2007). Akibat dari perubahan fungsi tersebut menyebabkan penurunan kemampuan fisik lansia sehingga terjadi penurunan produktifitas lansia di bidang ekonomi dan sosial. Hal tersebut dapat menjadi stressor tersendiri bagi lansia. Jika hal ini terus menerus dibiarkan akan menimbulkan masalah kesehatan jiwa pada lansia (Gilbert, 2007; Sadock, 2010).

Masalah kesehatan jiwa yang dialami oleh lansia adalah depresi dan kecemasan (Mohamed \& Abd-Elhamed, 2011; Montesó, dkk, 2012; Goyal \& Kajal, 2014; Hoover, dkk, 2010). Angka kejadian depresi di dunia sebesar 4,4\% dan kecemasan 3,6\% (WHO, 2015). Dari angka tersebut depresi lebih tinggi dari pada masalah kecemasan yang dialami lansia. Prevalensi depresi di Benua Asia menempati angka kejadian depresi sebesar $27 \%$, di Benua Amerika angka kejadian 15\%, di Benua Eropa
$12 \%$, di Benua Afrika 9\%. Angka-angka ini menunjukkan bahwa angka depresi pada lansia sangat tinggi (WHO, 2015). Melihat angka kejadian depresi di beberapa benua yang ada di dunia, Benua Asia paling banyak yang mengalami depresi (WHO, 2015). Pendekatan spiritual bagi lansia memiliki tujuan memberikan ketenangan dan kepuasan batin dalam berhubungan dengan Tuhan. Pada pendekatan spritual ini, setiap lansia akan menunjukkan reaksi yang berbeda-beda dalam menghadapi peristiwa kehilangan ataupun kematian (Wahjudi, 2008). Salah satu aspek dari spiritual adalah Aspek Eksistensial (Jeffrey \& Nevid, 2005).

Eksistensial merupakan hubungan individu dengan diri sendiri, lingkungan sosial dan masyarakat. Hubungan eksistensial ini mengacu pada tujuan dan kepuasan dari kehidupan, yang mengacu pada komponen eksistensial Rochat (2015). Hal serupa dinyatakan oleh Conradt-Eberlin (2014) bahwa aspek eksistensial merupakan ekspresi diri dari arti dan tujuan hidup, serta cara dalam berhubungan dengan diri sendiri dan orang lain.

Hasil studi literatur tentang depresi dan eksistensial menemukan adanya hubungan aspek eksistensial dengan depresi (Balboni, 2010; Ghobary, Hakimirad, \& Habibi, 2010; You, dkk, 2009 Dadfar, Bahrami, \& Dadfar, 2014; Mihaljevic, dkk, 2016). Perbedaan latar belakang budaya, tempat penelitian, kondisi demografi serta pelayanan kesehatan yang berbeda antara Indonesia dengan wilayah lainnya di luar Indonesia sehIngga perlu dilakukan penelitian dengan budaya yang berbeda. Selain faktor budaya yang membedakan dengan hasil penelitian lainnya adalah alat ukur yang digunakan dalam penelitian ini. Pada penelitian sebelumnya alat ukur yang digunakan adalah spiritual indeks well being scale (SIWB). Di dalam alat ukur itu tidak mencakup komponen religiusitas sebagai salah satu aspek dalam 
spiritual. Pada konteks budaya di Indonesia alat ukur tersebut menjadi tidak cocok untuk digunakan karena spiritual tidak dapat dilepaskan dari agama. Sehingga alat ukur yang dapat digunakan di Indonesia adalah alat ukur yang di dalamnya mengandung aspek eksistensial dan agama.

\section{METODE}

Penelitian ini merupakan penelitian kuantitatif dengan menggunakan pendekatan korelasional dilakukan secara potong lintang. Populasi pada penelitian ini adalah lansia di Balai Perlindungan Sosial Tresna Werdha (BPTSW) Ciparay Teknik pengambilan sampel dengan total sampling. Jumlah sampel pada penelitian ini 129 responden.

Peneliti menggunakan instrumen Spiritual Well-Being Scale (SWBS). Pernyataan SWBS berisi 20 item, pernyataan nomor $1,2,5,6,9,12,13,16$, dan 18 setiap item memiliki angka 1-6 dengan pilihan jawaban untuk masing-masing pernyataan adalah: Sangat Tidak Setuju (STS) dinilai 1, Cukup Tidak Setuju (CTS) dinilai 2, Tidak Setuju (TS) dinilai 3, Setuju (S) dinilai 4, Cukup Setuju (CS) dinilai 5, dan Sangat Setuju (SS) dinilai 6. Pernyataan nomor 3 , $4,7,8,10,11,14,15,17,19$, dan 20 pilihan jawaban untuk masing-masing pernyataan Sangat setuju (SS) dinilai 1, cukup setuju (CS)dinilai 2, setuju (S) diniai 3, Tidak setuju (TS) dinilai 4, Cukup tidak setuju (CTS) dinilai 5, Sangat tidak setuju (STS) dinilai 6. Hasil akhir adalah skor kesejahteraan spiritual, dimana total skor kesejahteraan spiritual antara 20-120. Semakin tinggi skor mencerminkan semakin sejahtera (Paloutzian, 2012) Terdapat tiga Aspek Eksstensial, yaitu rendah (skor 20-40), sedang (skor 41-99), dan tinggi (skor 100120) (Jahani, dkk, 2014) SWBS telah diterjemahkan dalam bahasa Spanyol, Portugis, China, Melayu, Arab dan Indonesia, serta sesuai dengan yang dimaksud dalam Bahasa Inggris. Reliabilitas alpha dan test retest menunjukkan kekuatan yang sama dengan aslinya, dimana nilai Alpha Cronbach dalam penelitian Nsamenang, dkk, (2016) memiliki $r=0,82$.

Instrumen untuk mengukur Depresi menggunakan Geriatric Depression Scale (GDS-15). GDS mengunakan skala Guttman. Jawaban 'tidak' untuk butir 1, 5, 7, 11, dan 13 mendapat skor 1. Jawaban 'ya' untuk butir 2, 3, 4, 6, 8, 9, 10, 12, 14, dan 15 mendapat skor 1 (Yesavage, 2007). Analisis yang digunakan dalam penelitian ini adalah analisis univariat dan analisa bivariat. Analisis univariat dilakukan terhadap data demografi. Penyajian data dari masingmasing variabel menggunakan tabel dan diinterpretasikan berdasarkan hasil yang diperoleh. Pada penelitian ini variabel dianalisis adalah jenis kelamin, usia, lama tinggal, status perkawinan, derajat depresi dan Pada tahap analisis bivariat peneliti menggunakan Uji Spearman karena memilki data ordinal-ordinal, hal ini dilakukan untuk menguji hubungan antara tingkat Religius dengan derajat depresi.

Sebelum melakukan analisis bivariat peneliti menggunakan uji Kolmogorof Smirnov Test dan Shapiro-Wilk untuk mengetahui uji normalitas data dan didapatkan hasil $p<0,001$. Karena nilai $p<0,05$ maka dinyatakan bahwa kelompok data berdistribusi tidak normal, untuk itu digunakan uji non-parametrik yaitu uji Spearman. Penelitian ini mendapat izin etik dari Surat persetujuan etik komisi Etik Fakultas Kedokteran Universitas Padjadjaran dengan nomor surat 612/ UN6.C.10/PN/2017. 
HASIL

Tabel 1 Data Demografi

\begin{tabular}{lcc}
\hline \multicolumn{1}{c}{ Karakteristik } & f & \% \\
\hline $60-74$ & 49 & 38,0 \\
\hline $75-90$ & 74 & 57,4 \\
\hline$>90$ & 6 & 4,6 \\
\hline Jenis kelamin & & \\
Laki-laki & 44 & 34,1 \\
Perempuan & 85 & 65,9 \\
\hline Status Pernikahan & & \\
Janda & 84 & 65,1 \\
Duda & 43 & 33,3 \\
Kawin & 2 & 1,6 \\
\hline Kunjungan keluarga & & \\
Pernah & 26 & 20,2 \\
Tidak pernah & 103 & 79,8 \\
\hline
\end{tabular}

Karakteristik responden sebagaimana ditampilkan di Tabel 1 menunjukkan bahwa responden pada penelitian ini paling banyak berusia antara 75-90 tahun, berjenis kelamin perempuan, dengan status pernikahan janda. Lebih dari tiga perempat responden tidak pernah menerima kunjungan keluarga.
Tabel 2. Distribusi Frekuensi Aspek Eksistensial

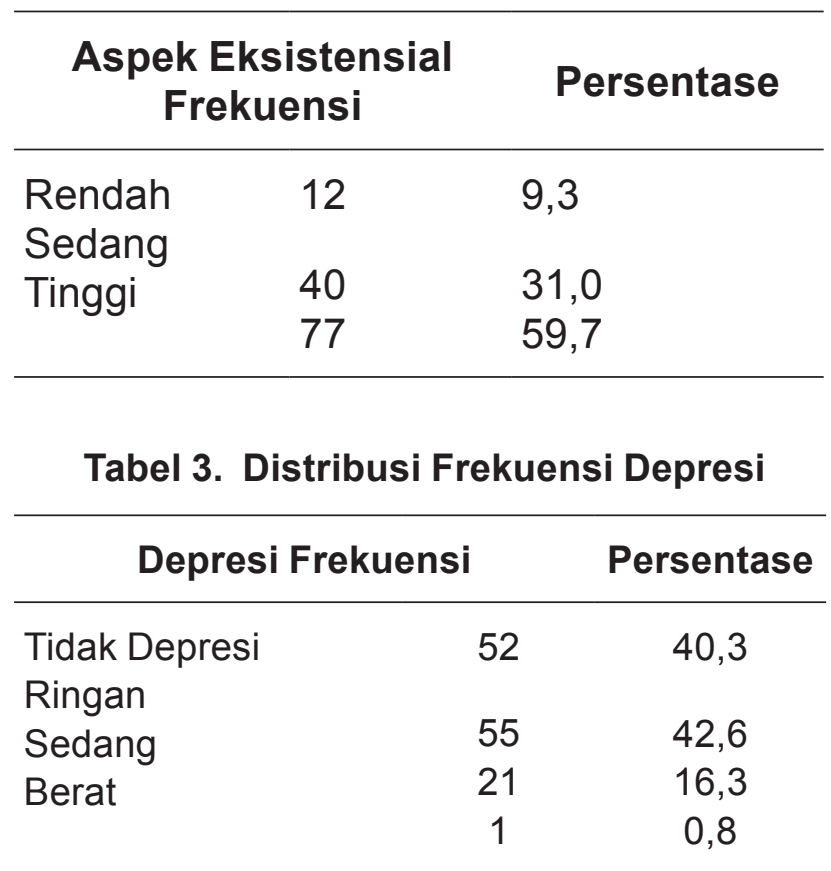

Berdasarkan Tabel 3 diketahui bahwa sebagian besar responden $(82,9 \%)$ tidak mengalami depresi dan tingkat depresi ringan, sedangkan hanya $17,1 \%$ yang mengalami depresi sedang-berat.

Tabel 4. Hubungan Aspek Eksistensial dengan Derajat Depresi Pada Lansia

\begin{tabular}{|c|c|c|c|c|c|c|c|c|c|c|}
\hline & & \multicolumn{7}{|c|}{ Derajat depresi } & & \multirow[b]{2}{*}{$\begin{array}{c}p \\
\text { Value }\end{array}$} \\
\hline & & $\begin{array}{c}\text { Tidak } \\
\text { Depresi }\end{array}$ & & Ringan & & Sedang & & Berat & & \\
\hline & & $f$ & $\%$ & $f$ & $\%$ & $f$ & $\%$ & $f$ & $\%$ & \\
\hline Aspek & Rendah & 0 & 0,0 & 1 & 8,3 & 10 & 83,3 & 1 & 8,3 & \multirow{3}{*}{0,001} \\
\hline \multirow{2}{*}{ Eksistensial } & Sedang & 6 & 15,0 & 26 & 65,0 & 8 & 20,0 & 0 & 0,0 & \\
\hline & Tinggi & 46 & 59,4 & 28 & 36,4 & 3 & 3,9 & 0 & 0,0 & \\
\hline
\end{tabular}

Berdasarkan Tabel 2, diketahui bahwa lebih dari setengahnya responden kesejahteraan eksistensial tinggi, dan cukup besar memiliki tingkat eksistensial rendahsedang $40,3 \%$.
Berdasarkan Tabel 4, diketahui bahwa antara Aspek religius dan depresi terdapat hubungan yang signifikan dengan korelasi sedang $(P<0,001)$ dengan $r$ tabel $-0,572$. 
Tanda negatif menunjukkan semakin tinggi aspek religius maka semakin rendah tingkat depresinya.

\section{Tempat penelitian}

Balai Perlindungan Sosial Tresna Werdha (BPSTW) Ciparay semula bernama Panti Sosial Tresna Werdha Pakutandang yang merupakan UPT Kanwil Departemen Sosial Provinsi Jawa Barat berdiri Tahun 1979 dan memulai operasionalnya pada tanggal 19 Mei 1980. Dengan dikeluarkannya Perda Nomor 5 Tahun 2002 Mengenai Perubahan atas Perda Nomor 15 Tahun 2000 Tentang Dinas Daerah, maka Panti Sosial Tresna Werdha berganti nama menjadi Balai Perlindungan Sosial Tresna Werdha (BPSTW) yang merupakan Unit Pelaksana Teknis Dinas pada Dinas Sosial Provinsi Jawa Barat. Dengan keluarnya Peraturan Gubernur Jawa Barat Nomor 113 Tahun 2009 tentang Organisasi dan Tata Kerja Unit Pelaksana Teknis Dinas dan Badan di Lingkungan Pemerintah Provinsi Jawa Barat maka BPSTW berganti nama menjadi Balai Perlindungan Sosial Tresna Werdha Ciparay Bandung dan Pemeliharaan Taman Makam Pahlawan.

\section{DISKUSI}

Hasil penelitian ini menunjukkan terdapat hubungan tingkat spiritualitas dengan tingkat depresi pada lansia di BPSTW Ciparay Provinsi Jawa Barat. Semakin tinggi tingkat aspek eksistensial seorang lansia maka semakin rendah tingkat depresinya, dan sebaliknya. Teori model eksistensial yang dikembangkan oleh Ellis \& Roger (1995) dalam Report, (2009) mengatakan bahwa gangguan jiwa terjadi bila individu gagal menemukan jati diri. Hal ini berarti jika lansia tidak tahu siapa diri mereka dan apa tujuan mereka hidup maka lansia tersebut merasa gagal dalam menemukan jati diri sehingga berpotensi besar mengalami depresi (Vivat, dkk, 2013). Berdasarkan hasil pengumpulan data, dari kedua aspek spiritualitas, aspek yang paling dominan mempengaruhi spiritualitas adalah aspek eksistensial. Hal tersebut disebabkan dalam aspek kesejahteraan eksistensial mencakup tentang pengalaman hidup, arah hidup yang dituju, masa depan, konflik dan ketidakbahagiaan dalam hidup.

Pada penelitian ini, sebagian besar lansia memiliki spiritualitas yang sedang. Lansia dengan spiritualitas sedang pada umumnya memiliki kemampuan untuk menggunakan sumber dan kekuatan dalam diri sendiri, mempunyai perasaan yang berkaitan dengan Tuhan, diri sendiri, orang lain, dan lingkungan. Hal ini sejalan dengan pendapat Potter \& Perry (2005) bahwa dengan harmonisasi antara diri sendiri dengan orang lain, alam dan kehidupan yang tertinggi yang berkaitan dengan Tuhan maka dapat menemukan makna, tujuan, dan nilai hidup, serta kebutuhan akan harapan seseorang.

Peran perawat dalam memenuhi kebutuhan spiritual lansia adalah dalam upaya memenuhi fungsi caring perawat. Sesuai dengan teori model keperawatan Jean Watson menurut Alligood (2014), peran perawat dalam membantu lansia untuk menemukan rasa spiritual seperti menemukan makna hidup dan harmonisasi selama masa yang kompleks. Selain itu, perawat dapat membantu lansia memenuhi kebutuhan spiritualnya seperti dengan memfasilitasi pemenuhan kebutuhan spiritual lansia, walaupun perawat dan lansia tidak mempunyai keyakinan spiritual atau keagamaan yang sama.

Pengukuran aspek eksistensial menggunakan alat ukur nyata yang menggambarkan dimensi agama dan existensial diri dalam spiritualitas individu. SWBS banyak dikembangkan dalam beberapa bahasa dunia antara lain Indonesia, Malaysia, Spanyol, 
Portugis, China dan Arab. Uji validitas telah dilakukan dengan nilai $r>0,80$ (Imam, dkk, 2009; Musa \& Pevalin, 2012. SWBS tepat digunakan di Indonesia karena ada kesamaan dalam hal dan budaya. Terkait dengan budaya keagamaan di budaya Timur yang lebih mengedepankan sistem doktrinisasi dalam hal spiritual. Faktor budaya di dalam penelitian ini mayoritas bergama Islam dan suku Sunda. Kebudayaan Indonesia selalu mengedepankan peningkatan spiritual dan praktik kebudayaan. Peningkatan spiritual ini akan memengaruhi individu dalam keyakinan akan kesembuhan (Goyal \& Kajal, 2014).

Faktor lain yang terkait dengan peningkatan aspek eksistensial adalah faktor usia. Hal ini sejalan dengan Kozier (2010) pada perkembangan usia dewasa tua, perkembangan ini diawali dengan semakin kuatnya kepercayaan diri yang dipertahankan walaupun menghadapi perbedaan keyakinan yang lain dan lebih mengerti akan kepercayaan dirinya. Aspek religius menggambarkan hubungan individu dengan Tuhan dan proses hubungan individu dari diri individu dalam dimensi spiritual atau secara garis besarnya adalah indikator dari kualitas hidup individu dalam dimensi spiritual atau secara garis besarnya adalah indikator dari kesehatan spiritualnya (Puchalski, 2012). Depresi merupakan suatu sindrom yang ditandai dengan sejumlah gejala klinis yang manifestasinya bisa berbeda pada masingmasing individu. Gejala depresi termasuk penurunan mood seperti murung, sedih, rasa putus asa, kesepian, dan tidak bahagia (Stuart 2013; WHO, 2014; Jilks, 2007). Umumnya perasaan yang secara dominan muncul adalah perasaan tidak berdaya dan kehilangan harapan. Depresi pada lansia seringkali tidak terdeteksi karena mereka lebih memfokuskan pada keluhan fisik yang sebenarnya adalah penyerta dari gangguan mental-emosionalnya. Hal ini sesuai dengan penelitian yang dilakukan
Wu, dkk (2015) bahwa lansia cenderung tidak memperdulikan perubahan perasaan yang dialaminya dan menganggap hal itu biasa saja sehingga menyebabkan suatu keadaan yang tidak sehat secara mental terus menetap dan depresi pun berkembang.

Spiritualitas dan agama berperan penting dalam kehidupan lansia (Puchalski, 2012). Spiritualitas membantu mengatasi masalah akibat perubahan-perubahan dalam kehidupan dan membantu lansia untuk menghadapi hari esok. Pengalaman spiritual sehari-hari memiliki hubungan yang positif dengan rasa bahagia, optimis, menghargai diri sendiri, menerima kehidupan yang dimiliki. Beberapa lansia mengatakan bahwa mereka menerima semua keadaan yang dialami dan meyakini bahwa apa yang terjadi kepada mereka sudah diatur oleh Yang Maha Kuasa. Spiritualitas mereka wujudkan melalui kegiatan keagamaan seperti membaca kitab suci, berdoa, dan sholat, menghadiri pengajian dan ceramah yang diadakan oleh pihak panti.

Pencapaian kesejahteraan spiritual pada responden yang tinggal di panti sangat berhubungan dengan menurunnya derajat depresi pada lansia. Ini merupakan cerminan dari pemahaman lansia dengan merasakan hubungan dengan kekuatan tertinggi dan orang lain, dan dapat menemukan arti tujuan hidup akan dapat beradaptasi lebih baik sehingga dapat membantu mencapai potensi lansia dan peningkatan kualitas hidup (Killian \& Penfield, 2012).

Menurut asumsi peneliti pendampingan spiritual pada lansia sangat diperlukan karena spiritual bersifat dinamis sehingga perlu adanya monitoring spiritual di panti. Perawat dapat melakukan pengkajian kesejahteraan spiritual yang bersifat holistik, karena hal tersebut menunjukkan bentuk pelayanan dan dukungan (Potter \& Perry, 2009). Terpenuhinya pemenuhan kebutuhan spiritual, maka lansia akan 
mencapai kesejahteraan spiritual. Individu yang memiliki pemahaman kesejahteraan spiritual merasakan hubungan dengan kekuatan tertinggi dan orang lain, dan dapat menemukan arti dan tujuan hidup sehingga dapat membantu mengurangi gejala terjadinya depresi pada lansia.

\section{SIMPULAN}

Terdapat hubungan aspek eksistensial dengan tingkat depresi pada lansia di BPSTW Ciparay Provinsi Jawa Barat dengan kekuatan hubungan yang sedang dan berpola negatif, artinya semakin tinggi tingkat eksistensial seorang lansia maka semakin rendah tingkat depresinya, dan sebaliknya. Implikasi untuk keilmuan keperawatan, berdasarkan hasil penelitian ini perawat dapat melakukan promosi kesehatan jiwa terhadap lansia yang tidak mengalami depresi dan depresi ringan. Sedangkan untuk lansia yang mengalami depresi sedang, perlu dilakukan upaya preventif. Adapun untuk lansia yang mengalami depresi berat, perawat dapat berkolaborasi dengan psikiater. Perawat dapat meningkatkan fungsi caring untuk membantu memenuhi aspek eksistensial lansia melalui asuhan keperawatan yang komprehensif yang meliputi bio-psiko-sosiospiritual.

\section{DAFTAR PUSTAKA}

Alligood, M. R. (2014). Nursing Theorist and Their Work (8th ed.). Missouri: Elsevier Inc.

Balboni, T. A., Paulk, M. E., Balboni, M. J., Phelps, A. C., Loggers, E. T., Wright, A. A., Block, S. D., ..., Prigerson, $\mathrm{H}$. G. (2010). Provision of spiritual care to patients with advanced cancer: Associations with medical care and quality of life near death. Journal of Clinical Oncology, 28: 445-452.
Boedhi-Darmojo, R. \& Martono, H. H. (2009). Buku ajar geriatric (IImu Kesehatan Usia Lanjut). Jakarta: Balai penerbit FK UI.

Chalise, H. N. (2014). Depression among elderly living in Briddashram (old age home). Advances in Aging Research, 3(1): 6-11. https://doi. org/10.4236/aar.2014.31002

Conradt-Eberlin, V. (2014). A rationale for addressing the spiritual needs of the elderly and adapting a framework for incorporating spiritual care into a nursing home (Order No. 1564388). Available from ProQuest Dissertations \& Theses Global. (1614530955). Retrieved from https://search.proquest.com/docvie w/1614530955?accountid $=17242$

Dadfar, M., Bahrami, F., \& Dadfar, F. (2014). The effectiveness of religious teachings in the treatment of Iranian depressed elders. European Geriatric Medicine, 5.

Ferszt, G. G., Miller, R. J., Hickey, J. E., Maull, F., \& Crisp, K. (2015). The Impact of a Mindfulness Based Program on Perceived Stress, Anxiety, Depression and Sleep of Incarcerated Women. Retrieved from https://doi.org/10.3390/ ijerph120911594

Ghobary, B., Hakimirad, \& Habibi. (2010). Relation between mental health and spirituality in Tehran University student. Procedia Social and Behavioral Sciences, 5: 887891. https://doi.org/10.1016/j. sbspro.2010.07.204

Gilbert, P. 2007. Psychotherapy and Counselling for Depression. London: SAGE Publications Ltd.

Goyal, A., \& Kajal, K. S. (2014). Prevalence of depression in elderly 
population in the southern part of punjab. Journal of family medicine and primary care, 3(4): 359-361. doi:10.4103/2249-4863.148109

Hoover, D. R., Siegel, M., Lucas, J., Kalay, E., Gaboda, D., Devanand, D. P., \& Crystal, S. (2010). Depression in the first year of stay for elderly long-term nursing home residents in the U.S.A. Int Psychogeriatr: 1161-1171. http://doi.org/10.1017/ S1041610210000578

Imam, S. S., Karim, N. H. A. K., Jusoh, N. R., Mamad, N. E.. (2009). Malay version of the SpiritualWell-Being Scale: Is Malay SpiritualWell- Being Scale a psychometrically sound instrument?. International Journal of Behavioral Science, 14(1): 72-83.

Jahani, A., Rejeh, N., Heravi-Karimooi, M., Vaismoradi, M., \& Jasper, M. (2014). Spiritual wellbeing of Iranian patients with acute coronary syndromes: a cross-sectional descriptive study. Journal of Research in Nursing, 19(6): 518-527. https://doi. org/10.1177/1744987114547606

Jeffrey S. \& Nevid, 2005. Concept of Anxiety. Jakarta: Rineka Cipta.

Jilks, J. 2007. Biopsychosocial Factors in Adult Depression and Implications for Counseling Practice. Retrieved from: http://www.jilks.com/articles/ Depression.html.

Killian, T. S., \& Penfield, M. (2012). Predictors of Depressive Symptoms: What Are the Roles of Geography and Informal Social Support?. Advances in Applied Sociology 2(4): 313-319.

Kozier. 2010. Buku Ajar Fundamental Keperawatan: Konsep, Proses dan Praktik. Jakarta. EGC
Mihaljevic, S., Aukst-margetic, B., \& Karnicnik, S. (2016). Do spirituality and religiousness differ with regard to personality and recovery from depression? A follow-up study. Comprehensiv Compr Psychiatry. 2016 Oct;70:17-24. doi: 10.1016/j. comppsych.2016.06.003. Epub 2016 Jun 14.

Musa, A. S. \& Pevalin, D. J. (2012). An Arabic version of the Spiritual Well-Being Scale. The International Journal for the Psychology of Religion, 22(2): 119-134.

Mohamed, E. M., \& Abd-Elhamed, M. a. (2011). Depression among elderly attending geriatric clubs in Assiut City, Egypt. The Journal of American Science, 7: 386-391. Retrieved from $<$ Go to ISI>://CABI:20123200359

Montesó, P., Ferre, C., Lleixa, M., Albacar, N., Aguilar, C., Sanchez, a., \& Lejeune, M. (2012). Depression in the elderly: Study in a rural city in southern Catalonia. Journal of Psychiatric and Mental Health Nursing, 19(5): 426-429. https://doi.org/10.1111/j.13652850.2011.01798.x

Nsamenang, S. A., Hirsch, J. K., Topciu, R., Goodman, A. D., \& Duberstein, P. R. (2016). The interrelations between spiritual well-being, pain interference and depressive symptoms in patients with multiple sclerosis. Journal of Behavioral Medicine, 39(2): 355-363. doi:http:// dx.doi.org/10.1007/s10865-0169712-3

Paloutzian, R. F. (2012). Retrieved from z.Oxford Txtbk Chap SWBS.pdf.

Potter, P. A. \& Perry, A. G. (2005). Buku Ajar Fundamental Keperawatan: Konsep, Proses, dan Praktik. Edisi 
4.Volume 2. (Alih Bahasa: Renata Komalasari, dkk). Jakarta: EGC.

Potter, P. A. \& Perry, A. G. (2009). Fundamental Keperawatan. Edisi 7. Jakarta: Salemba Medika

Puchalski, C. M. (2012). Spirituality in the cancer trajectory. Annals of Oncology, 23 (Suppl. 3): 49-55. doi; 10.1093/annonc/mds088.

Report, F. (2009). Depression in older age: A scoping study. National againg research(September), 1-102.

Rochat, E. (2015). Spiritual Needs of Hospitalized Older Adults. Arizona Center and Ageing, Families in society: the journal of contemporary human services 94(4): 284-291.

Sadock, S. \&. (2010). Kaplan \& Sadock's Synopsis Psikiatri llmu pengetahuan dan prilaku Psikiatri klinis. Jakarta: Binarupa Aksara.

Stanley \& Beare (2007). Buku Ajar Keperawatan Gerontik. Jakarta: EGC

Stuart, G.W. (2013). Buku Saku Keperawatan Jiwa, ed 5. EGC, Jakarta

Vivat, B., Young, T., Efficace, F., et al. (2013). Cross-cultural development of the EORTC-SWB 36: A stand-alone measure of spiritual well-being for palliative care patients with cancer. Palliative Medicine, 27, 457-469.

Wahjudi, N. (2008). Keperawatan Gerontik dan Geriatri Ed 3. Jakarta: EGC

World Health Organization. (2014). Ageing and Life Course. Retrieved from: http://www.who.int/ageing/en/.

World Health Organization. (2015). Definition of an older or elderly person. Retrieved from http:// www.who.int/healthinfo/survey/ ageingdefnolder/en/

Wu, B., Chi, I., Plassman, B. L., \& Guo, M. (2010). Depressive symptoms and health problems among Chinese immigrant elders in the US and Chinese elders in China. Aging \& Mental Health, 14(6): 695-704. https://doi. org/10.1080/13607860802427994

You, K. S., Lee, H., Fitzpatrick, J. J., Kim, S., Marui, E., Lee, J. S., \& Cook, P. (2009). Spirituality, Depression, Living Alone, and Perceived Health Among Korean Older Adults in the Community. Archives of Psychiatric Nursing, 23(4): 309-322. https://doi. org/10.1016/j.apnu.2008.07.003 